\title{
Organocatalyzed Closed-Loop Chemical Recycling of Thermo- Compressed Food Packaging Films of Poly(ethylene furanoate)
}

Elena Gabirondo ${ }^{a}$, Beatriz Melendez-Rodriguez ${ }^{b}$, Carmen Arnal ${ }^{b}$, Jose M. Lagaron ${ }^{b}$, Antxon Martínez de Ilarduya ${ }^{c}$, Haritz Sardon ${ }^{a^{*}}$, Sergio Torres-Giner ${ }^{\mathrm{b}}$ *

Monomers derived from renewable feedstocks have emerged as a novel sustainable alternative to petrochemical polymers. One of the biomass derived polymers that is recently gaining attention for food packaging applications is poly(ethylene furanoate) (PEF). However, PEF is not biodegradable and its endof-life options must be considered in order to avoid contributing to the accumulation of plastic waste. In this paper, after analyzing the suitability of PEF for packaging applications using an industrially relevant film-processing method, the chemical glycolysis of PEF was investigated using a thermally stable acid-base organocatalyst. After succesfully deconstructing the PEF films into bis(2-hydroxyethyl)-furan-2,5dicarboxylate (BHEF), the obtained BHEF was used to resynthesize PEF using the same organocatalyst to sucessfully generate a biopolymer with similar chemical and thermal properties to virgin PEF following a closed-loop cycle according to the Circular Economy principles.

\section{Introduction}

There are two main strategic goals in the development of biorefineries: the displacement of petroleum in favor of renewable raw materials and the establishment of a robust bio-based industry, the so-called Bioeconomy. ${ }^{1}$ Based on this concept, chemicals from various vegetable feedstocks such as sugars, starch, lignocelluloses, vegetable oils, organic acids or glycerol have been proposed as renewable monomers for polymer production. ${ }^{2}$ In particular, the dehydration of abundant 6-carbon sugars (e.g. fructose and galactose) to give furans is a well-known transformation for the preparation of furfurals such as 5-hydroxymethylfurfural (HMF) and 5-methoxy methyl furfural (MMF) with high selectivity ( 80\%) and conversion ( $90 \%$ ) rates. ${ }^{3}$ The oxidation of HMF, MMF, and their ethers in air over different catalysts ${ }^{4,5}$ yields furan-2,5-dicarboxylic acid (FDCA). This furanic compound has been identified as a strategic renewable building block to replace petroleum derived terephthalic acid (TA) in the production of polyesters. ${ }^{6}$ Although the current conversion of furfurals into FDCA only reaches yields of $50-60 \%$, this process is based on mild process conditions and requires low process energy requirements. ${ }^{7,8}$

Petrochemical PET currently has the largest market volume for beverage packaging and is widely used in film applications with a total world production capacity of over 65 million tons of virgin polymer a year. ${ }^{9}$ While most PET is petroleum-based, PET can also be partly bio-sourced at $\sim 30 \%$ by using bio-based monoethylene glycol (bio-MEG). However, the TA monomer still remains petroleum-based due to technical and economic constraints. ${ }^{10,11}$ Since the production of FDCA and bio-MEG utilizes renewable sugars, poly(ethylene 2,5-furandicarboxylate), more commonly termed poly(ethylene furanoate) (PEF), currently represents an appealing bio-mass derived replacement to petrochemical PET. ${ }^{12}$ In this regard, Eerhart et al. ${ }^{13}$ showed that replacing petroleum-based PET with PEF would reduce the non-renewable energy use by $40-50 \%$ and the greenhouse gas (GHG) emissions by $45-55 \%$ for the cradle-to-grave system. Therefore, large-scale production of bio-sourced PEF will significantly reduce both greenhouse gas emissions and non-renewable energy usage compared to petroleum-sourced PET. ${ }^{13}$ 
Despite the fact that FDCA is one of the most stable known monocyclic furan derivatives, its thermal stability is somewhat lower than that of TA and, hence, it has recently been shown that polymerization conditions must be modified in order to obtain high molecular weights $\left(\mathrm{M}_{\mathrm{w}}\right){ }^{14,15}$ Melt polycondensation using FDCA and MEG yielded $\mathrm{M}_{\mathrm{w}}$ values in the range of 10,000-47,000 g/mol and dispersity ( $(\mathrm{)})$ of 1.3-2.4. High-M $\mathrm{M}_{\mathrm{W}}$ PEF has also been obtained by ring-opening polymerization (ROP) using stannous octoate as a catalyst. ${ }^{16,17}$ Using ROP, the final $M_{W}$ was $50,000 \mathrm{~g} / \mathrm{mol}$ and the dispersity was 1.4 . In another study, Knoop et al. ${ }^{18}$ also produced high- $\mathrm{M}_{\mathrm{W}} \mathrm{PEF}$ through a two-step process consisting of melt polymerization followed by solid-state polymerization (SSP).This combination of melt polycondensation with SSP has been identified as the best procedure to obtaining high $\mathrm{M}_{\mathrm{W}}$ values. ${ }^{19-21}$

While several studies have dealt with the optimization of the polymerization conditions to obtain high- $\mathrm{M}_{\mathrm{W}}$ PEF materials, so far little attention has been paid to the end-of-life assessment of this biopolymer. As in the case of PET, due to the lack of degradation in ambient conditions, mechanical recycling may be the easiest and cheapest method of recycling PEF. However, as in PET and other biopolyesters, the number of reprocessing cycles is limited and after recycling the physical properties of the material are diminished. ${ }^{22,23}$

One solution to close the loop of PEF without downcycling the properties is through chemical recycling. This process breaks down plastic waste into raw materials for the production of new highquality plastics. ${ }^{24}$ For instance, it has been shown that PEF-based macrocycles can be recovered when taking advantage of the cyclodepolymerization of PEF at highly diluted conditions. These macrocycles can subsequently be repolymerized into virgin-like materials. ${ }^{17}$ While this process can be carried out on a laboratory scale, its implementation on large scales still needs further development, as much more diluted conditions are required to obtain high yields. Apart from cyclodepolymerization, like other polyesters, PEF can be depolymerized by solvolysis. For example, Sipos et al. ${ }^{15}$ briefly investigated the methanolysis of PEF in the presence of sodium methoxide/methanol solution at $90^{\circ} \mathrm{C}$, but only moderate yields were obtained ( $60 \%)$.

Herein it is envisioned that using the solvolysis processes, the glycolysis of PEF leading to bis(2hydroxyethyl)-furan-2,5-dicarboxylate (BHEF) has great potential to close the loop. This process has been already been successfully implemented for PET (Figure 1a). ${ }^{25}$ The present study reports the preparation and characterization of PEF films and their subsequent chemical recycling to achieved a Circular Bioeconomy model (Figure 1b). To this end, commercial PEF pellets were shaped into films by thermocompression and characterized in terms of their mechanical, thermal, and barrier properties to evaluate their potential application in food and beverage packaging. Thereafter, depolymerization of the PEF film waste was carried out by glycolysis using bio-MEG and a thermally stable organic catalyst system, yielding the BHEF monomer that was finally repolymerized into PEF by melt polycondensation. 
a)
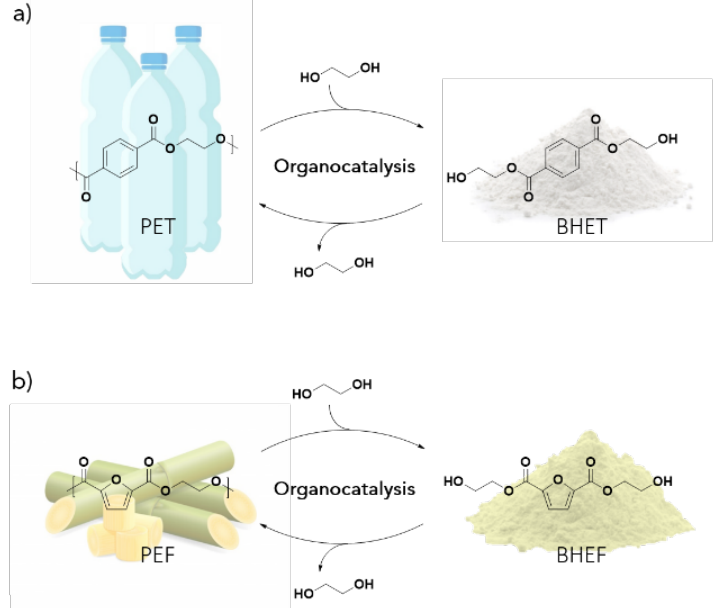

Figure 1. Scheme of the depolymerization by glycolysis and repolymerization using organocatalysts of a) polyethylene terephthalate (PET) and b) polyethylene furanoate (PEF) to yield bis(2-hydroxyethyl) terephthalate (BHET) and bis(2-hydroxyethyl)-furan-2,5-dicarboxylate (BHEF), respectively.

\section{Experimental}

\section{Materials}

PEF was supplied in the form of cylindrical pellets by AVA Biochem BSL AG (Muttenz, Switzerland). According to the manufacturer, its intrinsic viscosity is $0.557 \mathrm{dl} / \mathrm{g}$, weight- and number-average-molecular weights $\left(M_{W}, M_{n}\right)$ are $32,600 \mathrm{~g} / \mathrm{mol}$ and $12,400 \mathrm{~g} / \mathrm{mol}$, respectively, resulting in a $Ð$ value of 2.6. Bio-MEG, purum 99.8\%, was kindly provided by India Glycols Ltd. (Uttar Pradesh, India). Benzoic acid (BA) was purchased from Sigma-Aldrich S.A. (Madrid, Spain) and 1,8-diazabicyclo[5.4.0] undec-7-ene (DBU), 98\% of purity, was obtained from TCl (Eschborn, Germany) and distilled prior to use. Methanol, hexafluoro-2-propanol (HFIP), deuterated chloroform $\left(\mathrm{CDCl}_{3}\right)$, trifluoroacetic acid (TFA), and D-limonene with $98 \%$ purity were all supplied by Sigma-Aldrich S.A. (Madrid, Spain) and used without further purification.

\section{Preparation of PEF films}

The as-received PEF pellets were dried under vacuum at $80{ }^{\circ} \mathrm{C}$ for $12 \mathrm{~h}$ in order to remove any residual moisture and, thereafter, thermo-compressed into films using a hot-plate hydraulic press (Carver 4122, Wabash, IN, USA). To this end, the samples were first placed in the plates at $240{ }^{\circ} \mathrm{C}$ for 1 minute, without pressure, to remove any the residual moisture and then hot-pressed at 4-5 bars for $2 \mathrm{~min}$. The samples were removed from the press and cooled to room temperature in ambient conditions. Flat films with a thickness of $\sim \mathbf{1 0 0} \boldsymbol{\mu m}$ were obtained and stored in a desiccator at $25^{\circ} \mathrm{C}$ and $0 \% \mathrm{RH}$ for, at least, 48 $\mathrm{h}$ before characterization.

\section{Characterization methods}

\section{NMR spectroscopy}

High-resolution proton and carbon nuclear magnetic resonance $\left({ }^{1} \mathrm{H}\right.$ NMR and $\left.{ }^{13} \mathrm{C} N M R\right)$ spectra were collected in a Bruker DPX 300 spectrometer at 300.16 and $75.5 \mathrm{MHz}$ resonance frequency, respectively. A mixed solvent of $\mathrm{CDCl}_{3}$ and TFA at 8:1 (v/v) was used at room temperature. Experimental 
conditions were as follows: (a) ${ }^{1} \mathrm{H}$ NMR spectroscopy: $10 \mathrm{mg}$ of sample; $3 \mathrm{~s}$ acquisition time; $1 \mathrm{~s}$ delay time; $8.5 \mu$ s pulse; spectral width $5000 \mathrm{~Hz}$, and 320 scans. (b) ${ }^{13} \mathrm{C}$ NMR spectroscopy: $40 \mathrm{mg} ; 3 \mathrm{~s}$ acquisition time; 4 s delay time; 5.5 us pulse; spectral width $18800 \mathrm{~Hz}$, and more than 10000 scans.

\section{MALDI-TOF analysis}

Matrix Assisted Laser Desorption Ionization Time of Flight Mass Spectrometry (MALDI-TOF MS) measurements were performed on a Bruker Autoflex Speed system (Bruker, Germany) instrument, equipped with a $355 \mathrm{~nm}$ NdYAG laser using methanol as solvent and DCTB-NaTFA and DCTB-KTFA substrates.

\section{Gel permeation chromatography}

Gel permeation chromatography (GPC) was performed on a Waters equipment provided with refractive index (RI) and ultraviolet (UV) detectors. For this, $100 \mu \mathrm{L}$ of 0.1 (wt/vol) sample solution in HFIP was injected and the analysis was performed at a flowrate of $0.5 \mathrm{~mL} / \mathrm{min}$. HR5E and HR2 Waters linear Styragel columns $\left(7.8 \mathrm{~mm} \times 300 \mathrm{~mm}\right.$, pore size $\left.10^{3}-10^{4} \AA\right)$ packed with cross-linked polystyrene (PS) and protected with a pre-column were used. Molar mass averages and distributions were calculated against poly(methyl methacrylate) (PMMA) standards.

\section{Thermal properties}

Differential scanning calorimetry (DSC) measurements of the thermo-compressed PEF films were performed using a DSC8500 from Perkin Elmer, Inc. calibrated with indium and tin standards. The DSC scans were performed with approximately $5 \mathrm{mg}$ of film sample at a heating rate of $10{ }^{\circ} \mathrm{C} / \mathrm{min}$ from $-20^{\circ} \mathrm{C}$ to $250{ }^{\circ} \mathrm{C}$ and subsequent cooling down to $25^{\circ} \mathrm{C}$ under a nitrogen flow-rate of $20 \mathrm{~mL} / \mathrm{min}$. The percentage of crystallinity $\left(\mathrm{X}_{\mathrm{c}}\right)$ was calculated using Equation 1 :

$$
\left.\mathrm{X}_{\mathrm{C}}=\left[\frac{\Delta \mathrm{H}_{\mathrm{m}}-\Delta \mathrm{H}_{\mathrm{CC}}}{\Delta \mathrm{H}_{\mathrm{m}}^{0} \cdot(1-\mathrm{w})}\right] \cdot 100 \quad \text { (Equation } 1\right)
$$

Where $\Delta \mathrm{H}_{\mathrm{m}}$ and $\Delta \mathrm{H}_{\mathrm{CC}}(\mathrm{J} / \mathrm{g})$ correspond to the melting and cold crystallization enthalpies of PEF, respectively, and $\Delta \mathrm{H}_{\mathrm{m}}{ }^{0}(\mathrm{~J} / \mathrm{g})$ is the theoretical value of a fully crystalline $P E F$, which was taken as $137 \mathrm{~J} / \mathrm{g}^{26,27}$

Thermal stability was determined by thermogravimetric analysis (TGA) using a TGAQ500 from TA Instruments under nitrogen atmosphere. Samples of 5-10 mg were heated from 40 to $600{ }^{\circ} \mathrm{C}$ at a rate of $10^{\circ} \mathrm{C} / \mathrm{min}$. All thermal tests were performed in triplicate.

\section{Mechanical properties}

Tensile tests were performed using dumbbell-shaped film samples sizing $115 \mathrm{~mm} \times 16 \mathrm{~mm}$ using a Instron 4400 universal testing machine, equipped with a 1-kN load cell, from Instron (Norwood, MA, USA) according to the ASTM standard method D638. The tests were conducted using a cross-head speed of $10 \mathrm{~mm} / \mathrm{min}$. Samples were conditioned for $24 \mathrm{~h}$ prior to analysis and the tests were performed at room conditions, that is, at $40 \% \mathrm{RH}$ and $25^{\circ} \mathrm{C}$. A minimum of six specimens was tested.

\section{Barrier properties}

The gravimetric method ASTM E96-95 was used to determine the water vapor permeability (WVP) of the films. Payne permeability cups (diameter of $3.5 \mathrm{~cm}$ ) from Elcometer Sprl (Hermallfsous-Argenteau, Belgium) were filled with $5 \mathrm{~mL}$ of distilled water. The films were not in direct contact with water but exposed to $100 \% \mathrm{RH}$ on one side and secured with silicon rings. 
They were placed within a desiccator and sealed with dried silica gel at $0 \% \mathrm{RH}$ and $25{ }^{\circ} \mathrm{C}$. The control samples consisted of cups with aluminum films to estimate solvent loss through the seal. The cups were weighed periodically using an analytical balance $( \pm 0.0001 \mathrm{~g})$. WVP was calculated from the regression analysis of weight loss data versus time, whereas the weight loss was calculated as the total loss minus the loss through the seal. The permeability was obtained by multiplying the permeance by the film thickness. The limonene permeability (LP) was measured using a similar method as that for WVP, placing $5 \mathrm{~mL}$ of D-limonene inside the Payne permeability cups. The cups containing the films were placed at controlled room conditions of $40 \% \mathrm{RH}$ and 25 ${ }^{\circ} \mathrm{C}$. The limonene vapor permeation rate (LPRT) values were estimated from the steady-state permeation slopes and the weight loss was calculated as the total cell loss minus the loss through the seal. LP was calculated taking into account the average film thickness in each case. All the WVP and LP measurements were performed in triplicate.

Oxygen permeability (OP) was obtained from the oxygen transmission rate (OTR) measurements, recorded in duplicate, using an Oxygen Permeation Analyzer M8001 from Systech Illinois (Thame, UK) at $23{ }^{\circ} \mathrm{C}$ and $0 \%$ and $75 \% \mathrm{RH}$ to simulate both dry and humid packaging conditions. The samples were previously purged with nitrogen in the humidity-equilibrated samples and then exposed to an oxygen flow of $10 \mathrm{~mL} / \mathrm{min}$. The exposure area during the test was $5 \mathrm{~cm}^{2}$. Sheet thickness and gas partial pressure were determined. Measurements were performed in duplicate.

\section{Chemical recycling of PEF films}

A similar procedure to that described by Jehanno et. al. ${ }^{25}$ for the catalytic degradation of PET was followed. Briefly, $1 \mathrm{~g}$ of PEF film was placed with $5 \mathrm{~g}$ of bio-MEG in the presence of protic ionic salt of DBU:BA (0.020 g DBU: $0.017 \mathrm{~g} \mathrm{BA}$ ) in a $10 \mathrm{~mL}$ schlenk flask. The flask was closed and heated to $180{ }^{\circ} \mathrm{C}$ for $2 \mathrm{~h}$ under atmospheric pressure and vigorous stirring conditions until complete disappearance of any residual PEF. When the reaction was complete, the crude product was cooled to room temperature and a large excess of distilled water was added. The resulting solution was vortexed and filtered. Thus, the resultant aqueous transparent filtrate was stored at $4{ }^{\circ} \mathrm{C}$ in a refrigerator overnight. The precipitate was centrifuged and separated from the solution and finally dried at $40{ }^{\circ} \mathrm{C}$ for $24 \mathrm{~h}$.

\section{Repolymerization of PEF}

Polymerization of PEF was performed in two steps using the depolymerized product. The first one consisted of a melt polycondensation step, as described by Kasmi et. al. ${ }^{19,20}$ where the monomers react with each other by transesterification reactions and MEG units are formed and removed from the media. In this step, low- $\mathrm{M}_{\mathrm{W}}$ oligomers were formed. The second step was a SSP process in which the oligomers reacted one with the other to increase the $\mathrm{M}_{\mathrm{W}}$ of the biopolymer. The first polymerization unit consisted of a $100-\mathrm{mL}$ reactor glass batch reactor with 5 necks that was equipped with a gas inlet, a rotor with a stainless-steel blade, and gas outlet with a Vigreaux column at $140{ }^{\circ} \mathrm{C}$ connected to a distillation column with an open gas exit and graduated round glass flask. First, $46.7 \mathrm{~g}$ of the precipitate obtained from the depolymerization process and $1 \mathrm{~g}$ of DBU:BA salt catalyst were charged to the reactor. Then, the mixture was purged for 60 min with nitrogen at a flow-rate of $200 \mathrm{~mL} / \mathrm{min}$ at room temperature to remove the oxygen in the reactor 
headspace prior to the reaction. The temperature was raised to $170{ }^{\circ} \mathrm{C}$, under nitrogen atmosphere, and the reaction media was stirred at $80 \mathrm{rpm}$ for another $60 \mathrm{~min}$ in order to melt the reactant. Once the mixture was homogenized, the pressure was gradually reduced from $200 \mathrm{mbar}$ to 3.4 mbar over $1 \mathrm{~h}$ by connecting a vacuum pump Vacuubrand RZ 2.5 equipped with a VACUU·SELECT ${ }^{\circledR}$ vacuum controller (Vacuubrand GmbH \& Co. KG, Wertheim, Germany) to the gas exit and, thereafter, the temperature of the reaction system was slowly raised to $220{ }^{\circ} \mathrm{C}$ at 1 ${ }^{\circ} \mathrm{C} / \mathrm{min}$ for $1 \mathrm{~h}$ under a nitrogen atmosphere to avoid excessive foaming and minimize oligomer sublimation. The reaction was kept at $220{ }^{\circ} \mathrm{C}$ for $2 \mathrm{~h}$ and stirred at $80 \mathrm{rpm}$ and, finally, cooled to room temperature at room conditions. The viscous mass was removed from the reactor and milled in a IKA A11 basic analytical mill (IKA ${ }^{\circ}$-Werke GmbH \& Co. KG, Staufen, Germany). The resultant powder was gently washed overnight at room temperature with methanol under vigorous stirring to remove the excess of diol and dried overnight in a vacuum oven (Selecta Vaciotem-T, J.P. SELECTA, Barcelona, Spain) at $80^{\circ} \mathrm{C}$.

In the next step, SSP reaction was carried out in a SSP reactor donated by Prof. Cor Koning (DSM Coating Resins, Barcelona, Spain). To this end, $500 \mathrm{mg}$ of PEF oligomer powder was introduced in the SSP reactor. The reactor was purged with nitrogen gas heated at $200{ }^{\circ} \mathrm{C}$ using a flow rate of $10 \mathrm{~mL} / \mathrm{min}$. Approximately $50 \mathrm{mg}$ of samples were extracted at different times (from $0.5 \mathrm{~h}$ to $48 \mathrm{~h}$ ) and analyzed by ${ }^{1} \mathrm{H}$ NMR and GPC.

\section{Results and discussion}

\section{Film characterization}

Prior to analyzing the chemical recycling of the PEF film, further knowledge about its structureproperty relationship was carried out since it can be of prime interest in the framework of the optimization of its end-use properties in food packaging applications. To do so, commercially available PEF pellets were thermo-compressed into films and their thermal, mechanical, and barrier properties were determined and also compared with those of PET and other biopolyesters. Thermo-compression was selected since this melt processing methodology can be performed with small samples but it can also be easily scaled up and the film properties and processability can be compared and transferred to manufacturing processes such as compression molding or injection molding used for higher production volumes.

\section{Thermal Properties}

First, the thermal properties of the thermo-compressed commercial PEF film were analyzed and compared to the ones of PET (see Figure S1, which depicts their DSC thermograms recorded during the heating and subsequent cooling from the melt). It can be observed that the amorphous region of PEF showed a $\mathrm{T}_{\mathrm{g}}$ of $84^{\circ} \mathrm{C}$, which is similar to the ones reported by other authors ${ }^{12,27}$ and slightly higher than that of PET $\left(76-82{ }^{\circ} \mathrm{C}\right) .{ }^{28}$ Cold crystallization was not observed at higher temperatures and a sharp endothermic peak was observed at $220.5^{\circ} \mathrm{C}$, corresponding to the melting of the PEF crystals. Therefore, the $\mathrm{T}_{\mathrm{m}}$ value of PEF is lower than that of PET $\left(\sim 250-270{ }^{\circ} \mathrm{C}\right)$ by approximately $25^{\circ} \mathrm{C} .{ }^{29}$ Compared to PET, PEF usually shows a lower degree of crystallinity and lower rates of crystallization arising from the difference in geometry between FDCA and TA (see Table 1). ${ }^{30}$ These two facts will allow some energy to 
be saved in the processing step as lower temperatures will be required. It is worth noting that melting was observed in a single peak, which differs to that reported by both Knoop et al. ${ }^{18}$ and Berkel et al. ${ }^{32}$ The absence of cold crystallization and the presence of a single melting peak suggest that PEF developed a more perfect single crystal with a similar lamellae thickness during cooling after thermo-compression.

Thermogravimetric tests by heating at $10{ }^{\circ} \mathrm{C} / \mathrm{min}$ were performed on the PEF commercial sample under a nitrogen atmosphere and compared to commercial PET (see Figure S2). In the evolution of mass as function of temperature, it can be observed that PEF degradation occurred in a single step weight-loss process and that the thermal degradation profile of PEF was also similar to that observed for bio-PET, being above $300^{\circ} \mathrm{C}$, though its thermal stability was slightly lower. ${ }^{26,33}$

\section{Mechanical properties}

The mechanical properties of the thermo-compressed PEF film and a number of other biopolyesters are shown in Figure 2. The averaged values of Young's modulus $(E)$ and tensile strength at yield $\left(\sigma_{y}\right)$ were $3364 \pm 95 \mathrm{MPa}$ and $83.3 \pm 4.5 \mathrm{MPa}$, respectively, while the elongation at yield $\left(\varepsilon_{\mathrm{y}}\right)$ and break $\left(\varepsilon_{\mathrm{b}}\right)$ were 3.8 $\pm 0.8 \%$ and $4.1 \pm 0.6 \%$, respectively. For the industrial benchmark PET films, lower values of $E$ and maximum tensile strength $\left(\sigma_{\max }\right.$ ) have been reported, in the range of 1000-1100MPa and 50-600-50 MPa, respectively. ${ }^{34}$ However, in contrast to PEF, PET films displayed higher $\varepsilon_{\mathrm{b}}$ values of approximately $50 \%$ and 90\% for amorphous and semi-crystalline PET, respectively. ${ }^{34}$ Therefore, the PEF film showed a more brittle fracture behavior, which is further supported from the lack of plastic deformation in the tensile stress vs. strain curve (see Figure S3).

In comparison with other partially or fully bio-based polyesters, such as poly(3-hydroxybutyrate-co-3hydroxyvalerate) (PHBV), polylactide (PLA), and poly(butylene adipate-co-terephthalate) (PBAT), the PEF film tested here is also considerably more elastic and mechanically stronger. ${ }^{35}$ Its ductility is in the same range of that of PLA and PHBV, though significantly lower than that of PBAT, which is mostly used in mulch film and flexible packaging applications.

Table 1. Thermal properties of the thermo-compressed polyethylene furanoate (PEF) and polyethylene terephthalate $(P E T)$ films in term of: glass transition temperature $\left(T_{g}\right)$, melting temperature $\left(T_{m}\right)$, melting enthalpy $\left(\Delta H_{m}\right)$, and degree of crystallinity $\left(X_{c}\right)$, onset temperature of degradation $\left(T_{5 \%}\right)$, degradation temperature $\left(T_{\text {deg }}\right)$, and residual mass at $700{ }^{\circ} \mathrm{C}$.

\begin{tabular}{|c|c|c|c|c|c|c|c|c|}
\hline & \multicolumn{4}{|c|}{ DSC } & \multicolumn{4}{|c|}{ TGA } \\
\hline & $\mathrm{T}_{\mathrm{g}}\left({ }^{\circ} \mathrm{C}\right)$ & $\mathrm{T}_{\mathrm{m}}\left({ }^{\circ} \mathrm{C}\right)$ & $\Delta \mathbf{H}_{\mathrm{m}}(\mathrm{J} / \mathrm{g})$ & $X_{c}(\%)$ & $\mathrm{T}_{5 \%}\left({ }^{\circ} \mathrm{C}\right)$ & $\mathrm{T}_{\mathrm{deg}}\left({ }^{\circ} \mathrm{C}\right)$ & Mass loss (\%) & Residual mass (\%) \\
\hline PEF & $84.3 \pm 0.2$ & $220.5 \pm 2.7$ & $43.97 \pm 1.2$ & $32.1 \pm 0.8$ & $324.9 \pm 2.3$ & $396.7 \pm 3.4$ & $56.7 \pm 2.2$ & $10.6 \pm 0.2$ \\
\hline PET & 69 & 245 & 18 & 12.9 & 405.4 & 446.8 & 58.3 & 1.3 \\
\hline
\end{tabular}


It is also noteworthy that the mechanical properties of the thermo-compressed PEF film showed higher mechanical properties than those of injection-molded pieces prepared by Zhou and coworkers. ${ }^{36}$ The slightly higher mechanical properties of the thermo-compressed film in relation to some of the previously developed PEF articles may be related to the improved crystallinity.

In summary, whereas the low ductility of PEF can be limiting for flexible film applications, it can be useful for rigid articles and high strength fiber applications where a higher mechanical resistance is needed. Furthermore, the higher elasticity in combination with the higher $\mathrm{T}_{\mathrm{g}}$ will allow for improvement of the thermomechanical stability of the PEF films in comparison to those of PET, such as heat deflection temperature (TDT) or Vicat softening point

a)

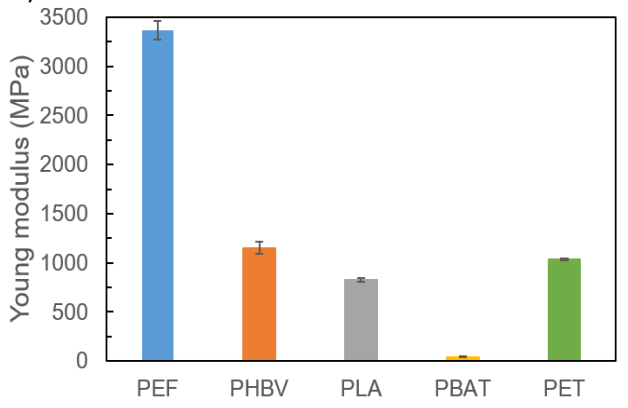

b)

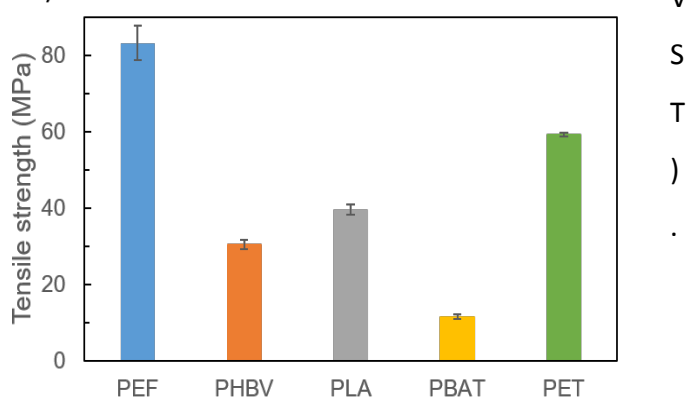

Figure 2. a) Young modulus; b) tensile strength of polyethylene furanoate (PEF), poly(3-hydroxybutyrate-co -3hydroxyvalerate) (PHBV), polylactide (PLA), and poly(butylene adipate-co-terephthalate) (PBAT) and polyethylene terephthalate (PET).

\section{Barrier properties}

Besides optimal thermal and mechanical properties, the key parameter for implementing a material in packaging applications is its response to different permeants such as vapors and gases. Figure $\mathbf{3}$ shows the permeability of the thermo-compressed PEF film to water and limonene vapors and oxygen gas. PEF showed a WPV value of $1.2 \times 10^{-15} \mathrm{~kg} \cdot \mathrm{m} \cdot \mathrm{m}^{-2} \cdot \mathrm{Pa}^{-1} \cdot \mathrm{s}^{-1}$, which is approximately 2.5 times less than of PET. The water permeability reduction for PEF vs. PET falls in the range to that of reported by Avantium ${ }^{37}$ and Burguess et al. $^{38}$ The aforementioned permeability reduction can be attributed to fundamental differences in segmental mobility that originate from the rigid furan moiety in PEF compared to the mobile phenyl moiety in PET. ${ }^{12}$ In comparison with other commercial biopolyesters, the water vapor barrier properties of PEF showed a slight improvement over PHBV $\left(1.82 \times 10^{-15} \mathrm{~kg} \cdot \mathrm{m} \cdot \mathrm{m}^{-2} \cdot \mathrm{Pa}^{-1} \cdot \mathrm{s}^{-1}\right)$ and were significantly superior to PLA $\left(12.31 \times 10^{-15} \mathrm{~kg} \cdot \mathrm{m} \cdot \mathrm{m}^{-2} \cdot \mathrm{Pa}^{-1} \cdot \mathrm{s}^{-1}\right) \cdot{ }^{35}$ Furthermore, its WPV is equivalent to that of low-density polyethylene (LDPE) $\left(1.20 \times 10^{-15} \mathrm{~kg} \cdot \mathrm{m} \cdot \mathrm{m}^{-2} \cdot \mathrm{Pa}^{-1} \cdot \mathrm{s}^{-1}\right)$ and close to that of polypropylene (PP) $\left(0.73 \times 10^{-15} \mathrm{~kg} \cdot \mathrm{m} \cdot \mathrm{m}^{-2} \cdot \mathrm{Pa}^{-1} \cdot \mathrm{s}^{-1}\right)$, some of the standard water barrier polymers used in food packaging applications. $^{39}$

Whereas both water vapor and oxygen barrier properties are important to avoid physical and chemical deterioration, limonene transport properties are usually used as a standard system to test aroma barrier in food packaging. It can be observed that LP of the PEF film was $1.7 \times 10^{-15} \mathrm{~kg} \cdot \mathrm{m} \cdot \mathrm{m}^{-2} \cdot \mathrm{Pa}^{-1} \cdot \mathrm{s}^{-}$ 1 , which nearly represents a 70 -fold reduction in aroma permeability in comparison to PET. This result can be attributed to the fact that PET is strongly plasticized by limonene and thus loses its dimensional stability. ${ }^{40}$ The high barrier of PEF against aroma certainly opens up new uses for food preservation for 
this biopolymer since it outperforms the barrier properties of current commercial biopolyesters such as PLA $\left(3.3 \times 10^{-15} \mathrm{~kg} \cdot \mathrm{m} \cdot \mathrm{m}^{-2} \cdot \mathrm{Pa}^{-1} \cdot \mathrm{s}^{-1}\right)$ and PHBV $\left(10.3 \times 10^{-15} \mathrm{~kg} \cdot \mathrm{m} \cdot \mathrm{m}^{-2} \cdot \mathrm{Pa}^{-1} \cdot \mathrm{s}^{-1}\right) .^{35}$

One can also observe that PEF exhibited significantly improved oxygen barrier properties as compared PET. In particular, the OP values of the PEF film were $0.30 \times 10^{-19} \mathrm{~m}^{3} \cdot \mathrm{m} \cdot \mathrm{m}^{-2} \cdot \mathrm{Pa}^{-1} \cdot \mathrm{s}^{-1}$ at $0 \% \mathrm{RH}$ and $0.92 \times 10^{-}$ ${ }^{19} \mathrm{~m}^{3} \cdot \mathrm{m} \cdot \mathrm{m}^{-2} \cdot \mathrm{Pa}^{-1} \cdot \mathrm{s}^{-1}$ at $75 \% \mathrm{RH}$. These conditions were chosen to describe more accurately the dry and humid conditions found in film packaging applications. Compared to PET, the values correspond to a permeability reduction of 10.8 times at $0 \% \mathrm{RH}$ and 4.6 times at $75 \% \mathrm{RH}$ for oxygen in PEF. The reduction attained in OP at low humidity is similar to that of ca. 11 times reported by Burguess et al., ${ }^{12}$ who explained it primarily by a difference in chain mobility, since both polyesters exhibit similar oxygen solubilities at $35^{\circ} \mathrm{C}$. Furthermore, the higher crystallinity attained in the thermo-compressed PEF films could also contribute to the improvement in the gas barrier properties. Finally, the PEF films also

a)

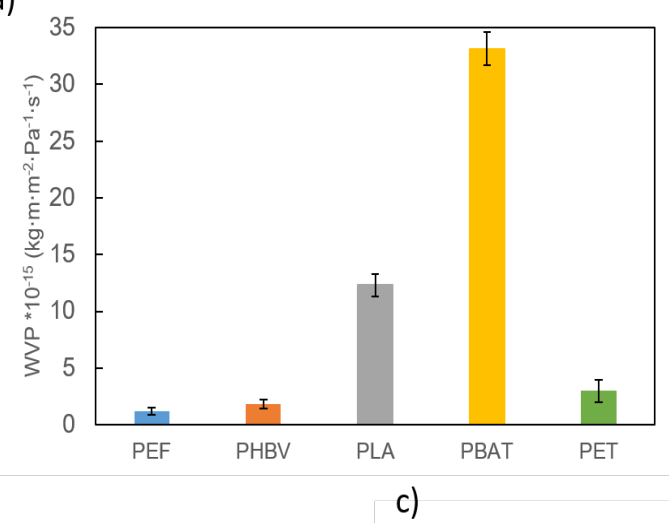

b)

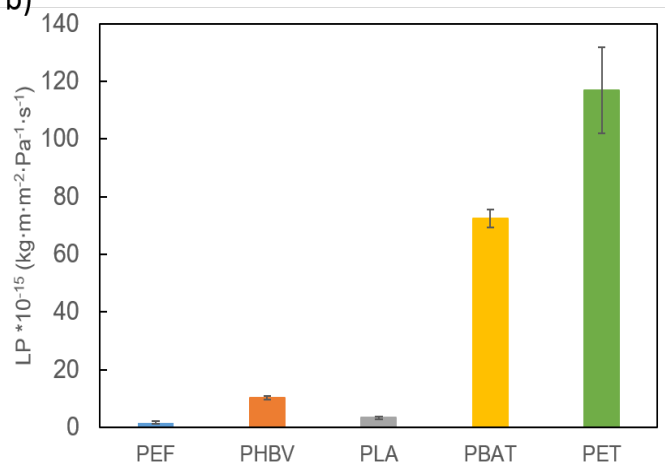

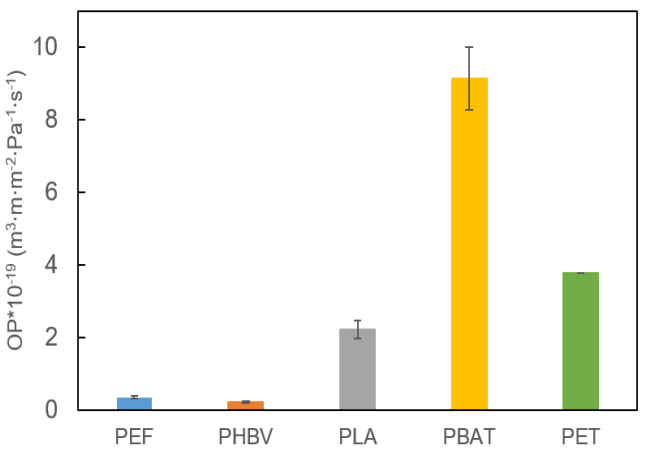

Figure 3. Permeability of a) water, b) limonene vapour and c) oxygen gas at for polyethylene furanoate (PEF), poly(3-hydroxybutyrate-co -3-hydroxyvalerate) (PHBV), polylactide (PLA), and poly(butylene adipate-co-terephthalate) (PBAT) and polyethylene terephthalate (PET).

outperformed the oxygen

barrier properties of films made of PLA, PHBV, and PBAT $\left(2.22,0.21\right.$, and $9.15 \times 10^{-18} \mathrm{~m}^{3} \cdot \mathrm{m} \cdot \mathrm{m}^{-2} \cdot \mathrm{Pa}^{-1} \cdot \mathrm{s}^{-1}$, respectively, measured at $60 \% \mathrm{RH}) .^{35}$

The permeability reduction for water, aroma, and oxygen further confirms the notion that PEF can potentially serve as a viable alternative to PET in the beverage market. Nevertheless, the significant oxygen barrier improvements for PEF compared to PET greatly expand the opportunities for introduction of PEF into markets beyond that of beverage applications such as barrier food packaging, particularly at 
low moisture conditions. This notion is complemented by PEF exhibiting improved mechanical strength but lower ductility and thermal properties compared to PET.

\section{Chemical Recycling of PEF film}

Although it offers excellent properties for packaging applications and the production of PEF represents an effective biomass derived replacement to petrochemical-based PET, sustainable end-of-life options should be sought for PEF in order for it to become a viable alternative to PET. PEF and PET are both nonbiodegradable and considering its current low production, chemical recycling is foreseen to be the best sustainable solution.

In this regard, the chemical glycolysis of PEF by using bio-MEG and the protic ionic salt DBU:BA at $180{ }^{\circ} \mathrm{C}$ as catalysts was investigated. As shown in Figure 4, the expected product of the reaction is BHEF, which is similar to the bis(2-hydroxyethyl) terephthalate (BHET) monomer obtained from the depolymerization of PET. $^{25}$

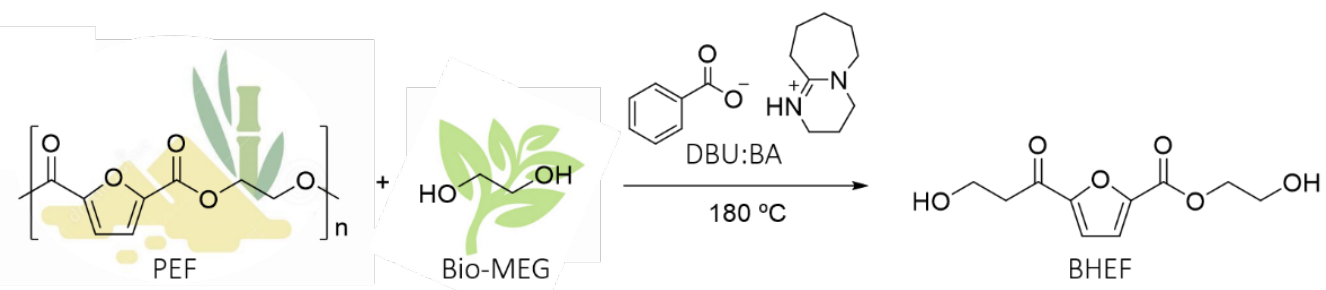

Figure 4. Depolymerization reaction of commercial polyethylene furanoate (PEF) with bio-based monoethylene glycol (bio-MEG) and catalyzed by 1,8-diazabicyclo[5.4.0]undec-7-ene:benzoic acid (DBU:BA) to yield the bis(2-hydroxyethyl)-furan-2,5-dicarboxylate (BHEF) monomer.

The catalyst DBU:BA used for this purpose is an acid-base mixture that combines the excellent catalytic ability of organic compounds with the thermal stability of metal-based catalysts, resisting degradation up to $>250{ }^{\circ} \mathrm{C}$, and has shown to be efficient to depolymerize PET. ${ }^{41}$ As the catalyst is soluble in water, it could be easily removed and recovered in the purification step and, thus, it could be reused. As shown in Figure 5, the reaction was completed in $2.5 \mathrm{~h}$ when using $5 \%$ catalyst at $180^{\circ} \mathrm{C}$. It was observed that at lower temperatures the reaction was considerably slower. With higher catalyst contents (7.5\%), the reaction was completed slightly faster, but without any significant improvement, while at $2.5 \%$ of catalyst

a)

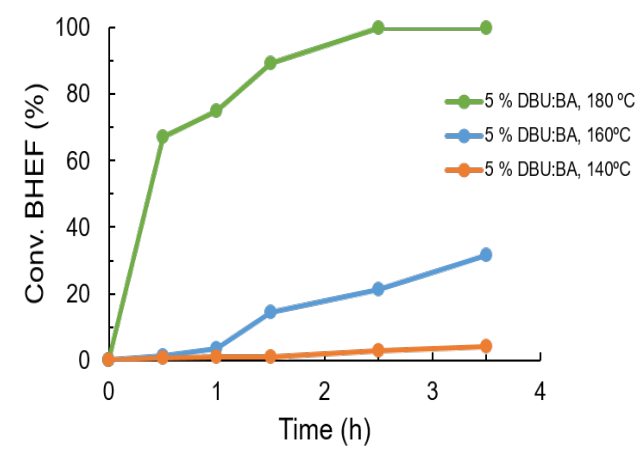

b)

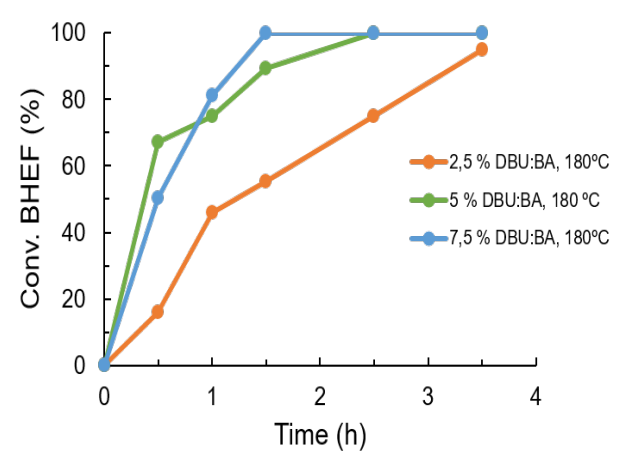

Figure 4. a) Influence of the temperature in the conversion speed and b) influence of the amount of catalyst in the conversion. 
the reaction was significantly slower. The kinetic data was used to calculate an activation energy of 163 $\mathrm{kJ} / \mathrm{mol}$, which justifies the high temperatures required to successfully depolymerize PEF (SI section).

The final product was analyzed using ${ }^{1} \mathrm{H}$ NMR and MALDI-TOF spectroscopy. Resonances in the ${ }^{1} \mathrm{H}$ NMR spectrum of the reaction product were at $\delta=4.0,4.5$, and $7.3 \mathrm{ppm}$, which are assigned to the ester linkage and confirmed the formation of BHEF (see Figure S4). The peaks at 4.0 and $4.5 \mathrm{ppm}$ belong to MEG monomer when attached to the furanoate and the signal at $7.3 \mathrm{ppm}$ to the furanoate ring. The additional low-intensity resonance seen at $4.7 \mathrm{ppm}$ indicates that other products than the desired BHEF were also formed, most likely corresponding to BHEF oligomers. In order to determine the presence of other species different from BHEF, the samples were further analyzed using MALDI-TOF spectroscopy. As found in the MALDI, together with the monomer, the BHEF dimer was also observed (see Figure S5). As the final goal was focused on

the repolymerization of the obtained BHEF into PEF, monomer and dimers were not separated.

After successfully achieving the chemical recycling of PEF, the obtained BHEF was investigated as a source to produce PEF by polycondensation. It was envisaged that BHEF would enable the repolymerization of PEF polymer by self-polycondensation as proposed in Figure 6. As in the case of PET, the BHEF monomer will enable the preparation low- $\mathrm{M}_{\mathrm{W}}$ PEF by melt condensation. In each condensation, a molecule of MEG is released and needs to be removed from the reaction media in order to promote the synthesis of the biopolymer and both vacuum and high temperatures are required. The process was performed using the same organocatalyst as for the depolymerization, that is, the DBU:BA mixture, and gradually increasing the temperature from $170{ }^{\circ} \mathrm{C}$ to $220^{\circ} \mathrm{C}$ and vacuum from 200 mbar to 3.4 mbar to minimize sublimation of the monomer. ${ }^{42}$<smiles>O=C(CCO)c1ccc(C(=O)OCCO)o1</smiles>

BHEF

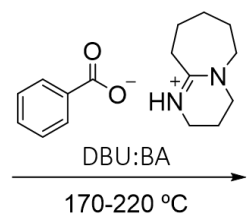

$170-220^{\circ} \mathrm{C}$

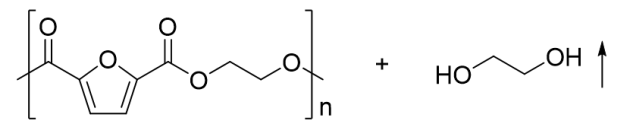

PEF
MEG

Figure 6. Melt polycondensation of polyethylene furanoate (PEF) starting from bis(2-hydroxyethyl)-furan2,5-dicarboxylate (BHEF).

a)

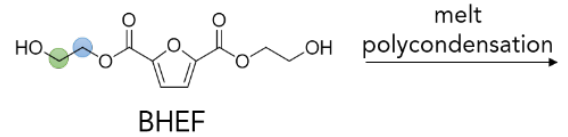

b)

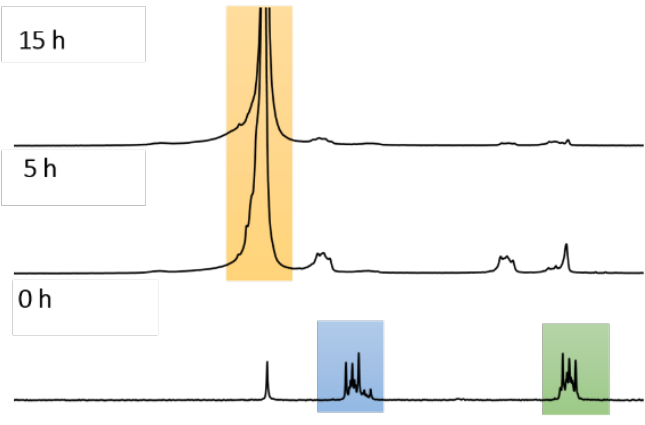

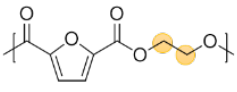

PEF oligomers solid-state polycondensation

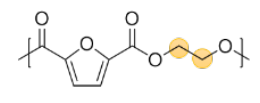

PEF polymer

c)

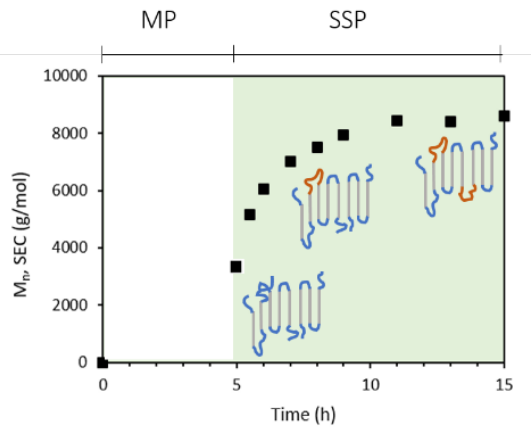

Figure 5. a) Synthesis process of polyethylene furanoate (PEF) in two stages (melt and solid-state polycondensation), b) High-resolution proton nuclear magnetic resonance $\left({ }^{1} \mathrm{H}\right.$ NMR) spectra of the reaction kinetics, and c) number-molecular weight $\left(M_{n}\right)$ evolution during the synthesis. 
Figure 7 shows the ${ }^{1} \mathrm{H}$ NMR spectrum of the melt-polycondensated product from BHEF. One can observe strong signals in region of 7.3 and $4.7 \mathrm{ppm}$ that correspond to the furanoate ring and the ethylene glycol unit respectively when they are linked by an ester bond. The ${ }^{1} \mathrm{H}$ NMR spectrum reported by Gandini et al. ${ }^{43}$ for PEF in deuterated trifluoroacetic acid (d-TFA or $\mathrm{CF}_{3} \mathrm{COOD}$ ) showed resonance of the $\mathrm{H} 3$ and $\mathrm{H} 4$ furan protons at $7.43 \mathrm{ppm}$, and that of the ester $\mathrm{CH}_{2}$ at $4.78 \mathrm{ppm}$ with the expected 1:2 integration ratio. After this first step, the attained $\mathrm{M}_{\mathrm{W}} \mathrm{s}$ were relatively low (up to $3400 \mathrm{~g} / \mathrm{mol}$ )

In order to obtain higher molecular weights, in a second stage, SSP was performed using the material obtained from the melt polymerization. In this process, the previously synthesized oligomers were heated at $200{ }^{\circ} \mathrm{C}$, which is above the $\mathrm{T}_{\mathrm{g}}$ and below the $\mathrm{T}_{\mathrm{m}}$ of PEF, in order to promote the growth of the chain in the amorphous regions of the oligomers. This post-condensation technique is environmentally benign compared to conventional melt polycondensation, as it is a solvent-free method and no toxic waste is released during the polymerization. ${ }^{21}$ The kinetics of the polymerization reaction was followed by ${ }^{1} \mathrm{H}$ NMR and GPC analysis. The evolution of $M_{n}, M_{W}, \oplus$, and the dimerization of PEF was analyzed over time during SSP (see further details in Table S1). One can observe that $\mathrm{M}_{\mathrm{W}}$ increased gradually with the reaction time up to $72600 \mathrm{~g} / \mathrm{mol}$ after $48 \mathrm{~h}$. During this process, the concentration of the biopolymer chains and the mobility of the end-group were enhanced. The overall increase of $M_{W}$ with long times is due to the elimination of by-products formed during SSP, which follows a diffusion-controlled mechanism. ${ }^{19}$ The highest $\mathrm{M}_{\mathrm{W}}$ value attained was approximately 2.2 times higher than that of the commercial one, though the $M_{n}$ was lower. One can also notice that $€$ remained in the range 2-3 for the first $8 \mathrm{~h}$ of reaction and, thereafter, it significantly increased to 5 and 8 after $24 \mathrm{~h}$ and $48 \mathrm{~h}$, respectively. It is also worth highlighting that the dimerization, which indicates the degree of MEG that dimerized before polymerization, was kept below the $1.8-2.2 \%$ range, being slightly lower than that attained in the commercial PEF sample. This observation can be related to the fact that SSP was implemented under relatively mild conditions and therefore fewer side reactions and thermal degradation can occur. ${ }^{18,20,21}$

The oligomer and polymer obtained after each step were also compared with the commercial PEF by DSC (see Figure S6). The oligomers that were synthesized after the melt polymerization (labeled as "PEF 5h") showed lower $\mathrm{T}_{\mathrm{g}}\left(85^{\circ} \mathrm{C}\right)$ and $\mathrm{T}_{\mathrm{m}}\left(210^{\circ} \mathrm{C}\right)$ values than the commercial polymer due to their reduced $\mathrm{M}_{\mathrm{W}}$ and higher monomer content. After SSP (“PEF 15h"), the transition temperatures increased, resulting in a $\mathrm{T}_{\mathrm{g}}$ value of $87^{\circ} \mathrm{C}$ and a $\mathrm{T}_{\mathrm{m}}$ of $224^{\circ} \mathrm{C}$. These values are in the range of that of commercial PEF, which showed a $\mathrm{T}_{\mathrm{g}}$ of $93{ }^{\circ} \mathrm{C}$ and $\mathrm{a} \mathrm{T}_{\mathrm{m}}$ of $213{ }^{\circ} \mathrm{C}$, confirming the successful recycling of PEF from its depolymerization and repolymerization of BHEF.

\section{Conclusions}

In this work, the suitability of bio-based PEF for food packaging applications using an industrially relevant film-processing method was studied. After physical characterization and comparison with PET and other biopolyesters, the depolymerization of commercial PEF was carried out by glycolysis using a bio-based glycol, bio-MEG, and a thermally stable organocatalyst, DBU:BA. After investigating and monitoring different depolymerization conditions, the depolymerization products were analyzed using ${ }^{1} \mathrm{H}-\mathrm{NMR}$ and 
MALDI, confirming the synthesis of BHEF monomer and dimer. The obtained recycled monomers were finally repolymerized by melt polycondensation followed by SSP to produce virgin-like PEF. The easy depolymerization process and the further repolymerization step can offer a sustainable end-of-life option for PEF to facilitate its industrial implementation in the food packaging sector.

\section{Acknowledgements}

The authors thank for technical and human support provided by IZO-SGI SGIker of UPV/EHU and European funding (ERDF and ESF). Authors gratefully acknowledge financial support from the Spanish Ministry of Science and Innovation (MICINN) trough project MAT2017-83373-R and the CiervaIncorporación contract IJCI-2016-29675 of Sergio Torres-Giner.

\section{References}

J. Wenger and T. Stern, Biofuels, Bioprod. Biorefining, 2019, 13, 1347-1364. 2014, 47, 1383-1391.

J. Ma, X. Yu, J. Xu and Y. Pang, Polymer, 2012, 53, 4145-4151.

E. De Jong, M. A. Dam, L. Sipos and G. J. M. Gruter, in ACS Symposium Series, American Chemical Society, 2012, vol. 1105, pp. 1-13. 
4191-4199.

N. Kasmi, G. Z. Papageorgiou, D. S. Achilias and D. N. Bikiaris, Polymers, 2018, 10(5), 471.

N. Kasmi, M. Majdoub, G. Z. Papageorgiou, D. S. Achilias and D. N. Bikiaris, Polymers, 2017, 9(11), 607

Y. Chebbi, N. Kasmi, M. Majdoub, G. Papageorgiou, D. Achilias and D. Bikiaris, Polymers, 2019, $11,438$.

A. Pawlak, M. Pluta, J. Morawiec, A. Galeski and M. Pracella, Eur. Polym. J., 2000, 36, 1875-1884.

V. Dulio, R. Po, R. Borrelli, A. Guarini and C. Santini, Angew. Makromol. Chemie, 1995, 225, $109-122$.

E. Gabirondo, A. Sangroniz, A. Etxeberria, S. Torres-Giner and H. Sardon, Polym. Chem., , DOI:10.1039/d0py00088d.

C. Jehanno, I. Flores, A. P. Dove, A. J. Müller, F. Ruipérez and H. Sardon, Green Chem., 2018, 20, 12051212.

G. Z. Papageorgiou, V. Tsanaktsis and D. N. Bikiaris, Phys. Chem. Chem. Phys., 2014, 16, 7946-7958.

G. Stoclet, G. Gobius Du Sart, B. Yeniad, S. De Vos and J. M. Lefebvre, Polymer, 2015, 72, 165-176.

S. Montava-Jorda, D. Lascano, L. Quiles-Carrillo, N. Montanes, T. Boronat, A. V. Martinez-Sanz, S. Ferrandiz-Bou and S. Torres-Giner, Polymers, 2020, 12(1), 174.

S. Torres-Giner, Y. Echegoyen, R. Teruel-Juanes, J. D. Badia, A. Ribes-Greus and J. M. Lagaron, Nanomaterials, 2018, 8(10), 745.

J. A. Moore and W. W. Bunting, in Advances in Polymer Synthesis, Springer US, Boston, MA, 1985, 51-91.

M. D. Sanchez-Garcia, E. Gimenez and J. M. Lagaron, J. Plast. Film Sheeting, 2007, 23, $133-148$.

J. G. van Berkel, N. Guigo, J. J. Kolstad, L. Sipos, B. Wang, M. A. Dam and N. Sbirrazzuoli, Macromol. Mater. Eng., 2015, 300, 466-474.

P. Ji, D. Lu, S. Zhang, W. Zhang, C. Wang and H. Wang, Polymers, 2019, 11, 2105.

S. Thomas and V. P. M., Handbook of engineering and specialty thermoplastics. Volume 3, Polyethers and polyesters, Scrivener, 2011.

L. Quiles-Carrillo, N. Montanes, J. M. Lagaron, R. Balart and S. Torres-Giner, J. Polym. Environ., 2019, 27, 84-96.

M. Jiang, Q. Liu, Q. Zhang, C. Ye and G. Zhou, J. Polym. Sci. Part A Polym. Chem., 2012, 50, $1026-1036$.

Avantium enters into the commercialisation phase for PEF | Bioenergy International, https://bioenergyinternational.com/biochemicals-materials/avantium-enters-into-the-commercialisationphase-for-pef, (accessed 5 May 2020).

S. K. Burgess, O. Karvan, J. R. Johnson, R. M. Kriegel and W. J. Koros, Polymer, 2014, 55, 4748-4756. 

2011, 669-691. Polym. J., 2018, 104, 170-176. 2009, 47, 295-298.<smiles>CC1(OCCOC(=O)c2ccc(C(C)(C)C)o2)CCCC1</smiles>

Polyethylene furanoate (PEF)

Repolymerization

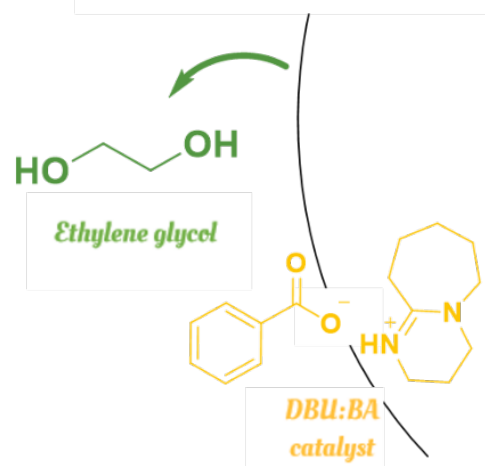

Bis(2-hydroxyethyl)

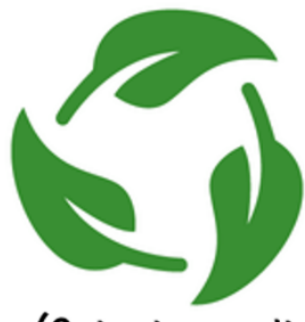

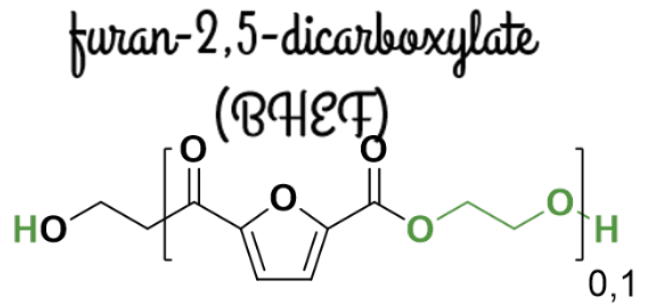

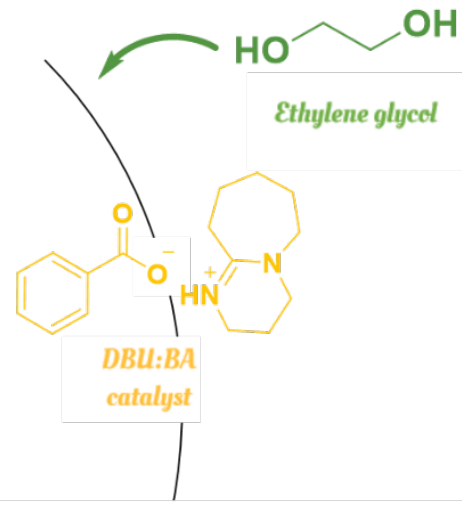

Depolymerization

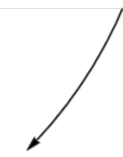

